\title{
Analytical Approach of Laser-Induced Breakdown Spectroscopy to Detect Elemental Profile of Medicinal Plants Leaves
}

\author{
Abdul Jabbar', Mahmood Akhtar', Shaukat Mehmood ${ }^{1}$, Koo Hendrik Kurniawan ${ }^{2}$, \\ Rinda Hedwig ${ }^{3}$, and Muhammad Aslam Baig, ${ }^{4 *}$ \\ ${ }^{1}$ Department of Physics, Mirpur University of Science and Technology (MUST), Mirpur-10250 (AJK), Pakistan \\ ${ }^{2}$ Research Center of Maju Makmur Mandiri Foundation, 40 Srengseng Raya, Jakarta 11630, Indonesia \\ ${ }^{3}$ Computer Engineering Department, Faculty of Engineering, Bina Nusantara University, \\ 9 K.H. Syahdan, Jakarta 11480, Indonesia \\ ${ }^{4}$ National Center for Physics, Quaid-i-Azam University Campus, 45320 Islamabad, Pakistan
}

*Corresponding author:

tel: $+92333-5205674$

email: baig77@gmail.com

Received: August 23, 2018

Accepted: October 29, 2018

DOI: $10.22146 /$ ijc. 38263

\begin{abstract}
Laser ablation chemical and spectroscopic studies of Calotropis procera, Chenopodium ambrosioides, and Nerium indicum leaves was performed using $1064 \mathrm{~nm}$ Nd: YAG laser in air at different pressure and time delay. These medicinal plant's leaves are used by local people for different diseases. The knowledge of medicinal and toxic metals in these plants is very important. We have presented time-resolved studies of different elements and how their lives change with different delay time. $\mathrm{C}, \mathrm{H}, \mathrm{Si}, \mathrm{Al}, \mathrm{Fe}$, $\mathrm{Cu}, \mathrm{Ca}, \mathrm{Mg}, \mathrm{Na}, \mathrm{K}, \mathrm{N}, \mathrm{O}, \mathrm{Sr}$ and Ba have been detected in all the three samples with a molecular form of Carbon and Nitrogen band. We have detected $C, H, N$, and $O$ as a major element while, $\mathrm{Fe}, \mathrm{Cu}, \mathrm{Mg}, \mathrm{K}$ and $\mathrm{Ca}$ as essential medicinal metals with other trace elements such as $\mathrm{Si}, \mathrm{Sr}, \mathrm{Al}$ and $\mathrm{Ba}$ in all the three plants leaves. We present $1 \mu$ s delay time is the best time for elements lifetime in time resolved studies. The behaviour of intensity with different pressures was also studied and it was concluded that 7 torr was the best pressure for the maximum value of intensity. In particular, the electron density and the temperatures of the plasma were reported. The temperature was calculated from the wellknown Boltzmann plot method and electron density was estimated from the stark broadened profile of the Ha line.
\end{abstract}

Keywords: CN band; medicinal plants; LIBS; time-resolve

\section{- INTRODUCTION}

Plants are very important for human health and create a healthy and safe environment for animals and human beings [1]. Plant-based medicines are using since ages. Increasing population day by day causes serious threats to the lives of plants due to their cutting and firing. Most remote areas people depend upon these herbal drugs for the treatment of diseases. Determination of essential and trace elements are important to check the efficiency and enhanced production of medicinal plants. The various elements can be transferred to these plants due to ground water basin, increasing pollution, dust, living area offlora, serious soil and polluted environment.
So it is essential to analyze them for any hazardous metal for safe and healthy use.

The main aim of our work was to check essential, major, trace and any toxic metal in these plants leaves which are using by common people for the treatment of different diseases by using relatively simple and fast technique which has minimal or no sample preparation. Due to the negligible or minimal sample preparation, LIBS is able to provide relatively cheap and rapid response for the detection of essential, major and trace elements in medicinal plants. LIBS technique has several advantages in terms of detection of multi-elements, analytical time, costs and the ability for microanalysis

Abdul Jabbar et al. 
with minimum sample amount. Some particularities are light-element detection, material identification, good reproducibility, depth profiling and quantitative analysis makes it versatile. The capability of fast analysis of solid, liquid, or gaseous samples and relative simplicity makes LIBS an ideal tool to study a wide range of samples.

For medicinal plants leaves this technique is feasible due to the above mentioned advantages over other conventional techniques like ICP-AES, AAS, EDXRF etc. These techniques requires sample preparations and involve solutions during their analysis process which may contaminate them and affect the qualitative and quantitative results. Line profiles of essential nutrients of these plants have also discussed at different time delay, energy and ambient pressures [2-5]. The detection of CN band is important to analyze actual content of $\mathrm{C}$ and $\mathrm{N}$ with $\mathrm{CN}$ band emission by LIBS. There are different analytical techniques like XRF, ICP-MS, AAS [6] are available for the detection of trace elements and other techniques like calorimetry, chromatography, or spectrophotometry [7] for the detection of molecular band, but they are sample destructive, requires use of chemicals for sample preparation, time-consuming, expensive and not eco-friendly. Avoids from these difficulties Laser-induced breakdown spectroscopy (LIBS) used as a versatile technique for analysis of solid, liquid and gaseous samples from the last couple of decades to obtain quantitative and qualitative information. LIBS have the capability to perform the direct multi-elemental analysis.

This technique involves the focusing of a high power laser pulse (tens to hundreds of $\mathrm{mJ}$ energy) on a target through a focusing lens. As a result, a luminous plasma is created which contains excited atomic and ionic species. This plasma is created when the breakdown threshold of the material is exceeded or crossed by laser irradiance. Radiations of the constituent elements are emitted off by the plasma as it cools down with time. A portion of this plasma light is collected through the optical fiber and spectrometer disperse this light into spectra comprises of different wavelengths. These wavelengths belong to specific elements. Spectroscopic analysis is then used to determine plasma parameters from the optical emission spectrum of plasma both qualitatively and quantitatively. These plasma parameters include electron number density and electron temperature [811]. From last couple of decades, LIBS have been a growing interest for the analysis of plants and agriculture samples [12-14]. A number of researchers discussed the dissociation of Nitrogen from ambient air to form chemical bonding with ablated Carbon from organic sample to form CN band [15-17]. Time-resolved LIBS study was performed on coal sample and special attention was paid on atomic and molecular spectra of carbon including $\mathrm{C}_{2}$ and $\mathrm{CN}$ [3]. Formation and emission characteristics of $\mathrm{CN}$ band in coal were studied using LIBS at low pressure [18]. Optical emission of LIBS on the surface of fresh vegetables provides direct measurements of trace elements studied by Lie et al. They were also compared molecular emission of $\mathrm{CN}$ from plants with temperature [19]. A detailed review on time-resolved application of LIBS have been discussed by [20]. $\mathrm{CN}$ and $\mathrm{C}_{2}$ molecules carry very important chemical information. These molecules have remarkable interest and the study of plasma plume expansion, collisional and laser-matter interaction has been discussed by a number of researchers [22-23]. Peng et al. studied leaves of rice plant for the detection of Chromium ( $\mathrm{Cr}$ ) and used $\mathrm{CN}$ band peak intensity as an identifier outliner [24]. Andrade et al. applied LIBS for the detection of toxic and essential elements from eighteen different samples [25]. LIBS have been used recently for analysis of Indian medicinal plants to study the concentrations of $\mathrm{C}, \mathrm{Ca}$ and $\mathrm{Mg}$ level in a spectral range between 200 and $500 \mathrm{~nm}$ [26]. For the analysis of Chinese medicinal herb Blumea balsamifera, LIBS technique was successfully applied to detect elemental composition based on $\mathrm{C}, \mathrm{Ca}$ and $\mathrm{Mg}$ concentrations in samples originating from Hainan and Guizhou provinces [27]. No study of medicinal plants with simultaneous detection of $\mathrm{CN}$ band with major and trace elements have been reported to best our knowledge.

The plants under analysis were collected from district Kotli Azad Jammu and Kashmir (AJK) that is situated in between longitude $73^{\circ} 6^{\prime}$ to $74^{\circ} 7^{\prime}$ east and latitude $33^{\circ} 20^{\prime}$ to $33^{\circ} 40^{\prime}$. It is about $700-1400 \mathrm{~m}$ above 
the mean sea level and is bounded on the eastern side by occupied Kashmir [28]. Studies on these plants have done by a number of botanists in these regions [28-31]. The Calotropis procera has several uses since ages and its roots (extremely poisonous) are applied as anti-dose for snakebite [32]. It is used in the treatment of skin diseases such as bullous dermatitis and hypertrophic scars [33].

Calotropisprocera is used in traditional medicine as a purgative, anthelmintic, anticoagulant, anticancer, antiinflammatory, antipyretic, analgesic and antimicrobial, to treat leprosy, leucoderma, ulcers, tumors, piles, diseases of the spleen, liver and abdomen [34]. Mahmood et al. in 2012 also reported indigenous medicinal knowledge of Calotropis procera from the same area where current samples were collected [31]. Nerium indicum is also widely used for medicinal purpose. The leaf decoction is used to reduce swellings. Macerated leaves are used for itch and fall of hair [35]. Chenopodium ambrosioides is a strongly aromatic, hairy, annual or perennial herbal plant [36]. It is abundant in many areas of Pakistan and has been reported to have a wide variety of medicinal and insecticidal properties [37]. It is used in constipation and stomach flatulence [38].

\section{- EXPERIMENTAL SECTION}

\section{Materials}

Calotropis procera, Chenopodium ambrosioides, and Nerium indicum leaves were collected from Kotli Azad Jammu and Kashmir and identified through the taxonomy Department of Quaid-i-Azam University Islamabad Pakistan. The samples were dried and pressed into pellets of thickness $2 \mathrm{~mm}$ and diameter $1.3 \mathrm{~cm}$ under a hydraulic pressure of $3 \mathrm{MPa}$. The measurement of the size of pellets is shown in Fig. 1. Details of these three plants are given in Table 1 and a picture of each plant is shown in Fig. 2.

\section{Instrumentation and Procedure}

The experimental setup is schematically shown in Fig. 3. Nd: YAG laser having $1064 \mathrm{~nm}$ wavelength and $8 \mathrm{~ns}$ delay time capable to deliver energy $200 \mathrm{~mJ}$ operated in Q switch mode at $10 \mathrm{~Hz}$ repetition rate and $100 \mathrm{~mJ}$ reduced output energy. The laser beam was focused on the sample through a convex lens whose focal length was $150 \mathrm{~mm}$. To yield a power density of $250 \mathrm{~W} / \mathrm{cm}^{2}$ focal length is with $-5 \mathrm{~mm}$ defocused condition was used. Another preliminary experiment was performed to determine the condition for the optimum value of energy to ablate target material for minimum ablation power density and reproducible intensities from the powder

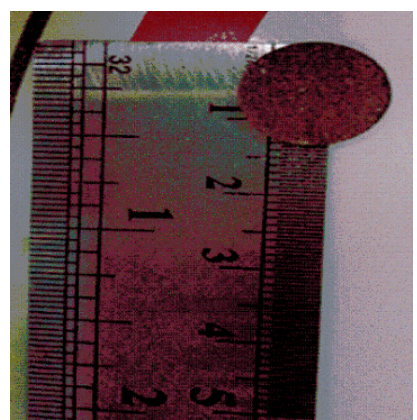

Fig 1. Pellet size measurements

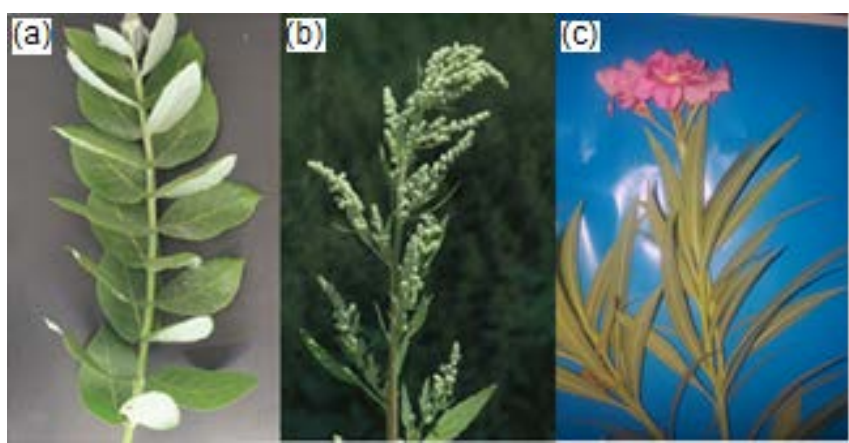

Fig 2. Three plants leaves of (a) Calotropis procera (b) Chenopodium amboriosides and (c) Nerium indicum used in this study

Table 1. Details of three plants (leaves)

\begin{tabular}{lllll}
\hline Plants & Kingdom & Division & Family & Common Name \\
\hline Calotropis procera & Plantae & Angiosperms & Apocynaceae & Ak \\
Chenopodium ambrosioides & Plantae & Angiosperms & Amaranthaceae & Batho \\
Nerium indicum & Plantae & Magnoliophyta & Apocynaceae & Ganira \\
\hline
\end{tabular}

Abdul Jabbar et al. 
sample excluding Copper $(\mathrm{Cu})$ sub target lines from the sample holder [39].

The experiment was done in a chamber equipped with an inlet and outlet ports for the ambient gas to maintain pressure at 30 torrs. In this experiment, the plasma emission intensity was collected by optical fiber cable having a $10 \mu \mathrm{m}$ core diameter. Its other end was connected to Echelle spectrograph (Mechelle M500 type equipped with gated ICCD system, 200-975 nm, Andor iStar ICCD) for wide range spectral measurements. The sample was rotated to avoid deep crater on each laser shot.

\section{- RESULTS AND DISCUSSION}

\section{Time-Integrated Studies}

We have recorded time-integrated spectra of all the three samples at the optimum value of energy and delay time. The fundamental wavelength of Nd: YAG laser was focused on the target of plants leave to produce plasma plume. The laser energy was $45 \mathrm{~mJ}$ and delay time was $1 \mu \mathrm{s}$.
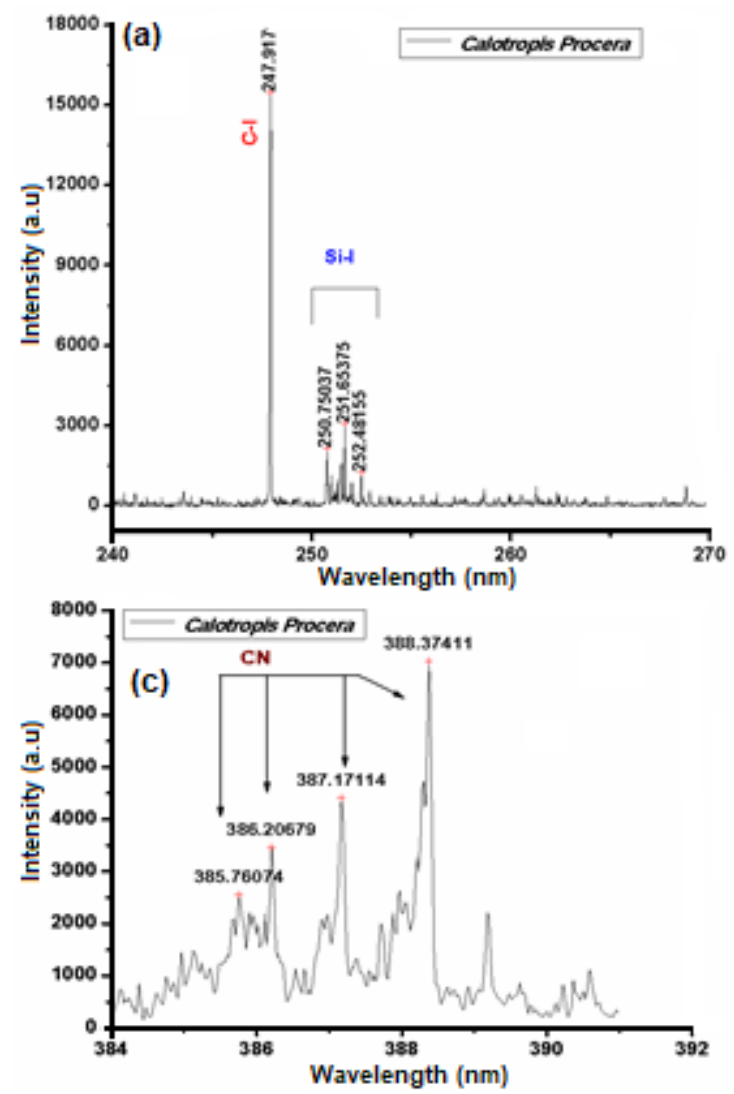

Each spectrum was recorded on average of 10 laser shots and spectrum shows good reproducibility under the same experimental conditions. Time-integrated spectra of Calotropis Procera recorded at $45 \mathrm{~mJ}$ is shown in Fig. 4. Fig. 4(a) shows Calotropis procera leaves spectrum range from 240 to $270 \mathrm{~nm}$ with C-I $247.85 \mathrm{~nm}$ line corresponding to transition $2 \mathrm{~s}^{2} 2 \mathrm{p} 3 \mathrm{~s}^{1} \mathrm{P}_{1} \rightarrow 2 \mathrm{~s}^{2} 2 \mathrm{p}^{2}{ }^{1} \mathrm{~S}_{0}$ and Si lines around $251 \mathrm{~nm}$ were observed. The common neutral C-I emission lines existing in the plume and other

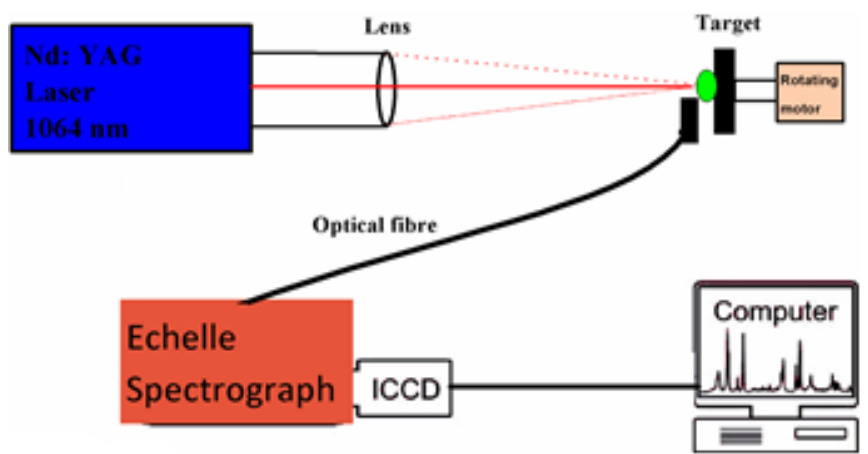

Fig 3. Experimental setup used for plants leaves analysis
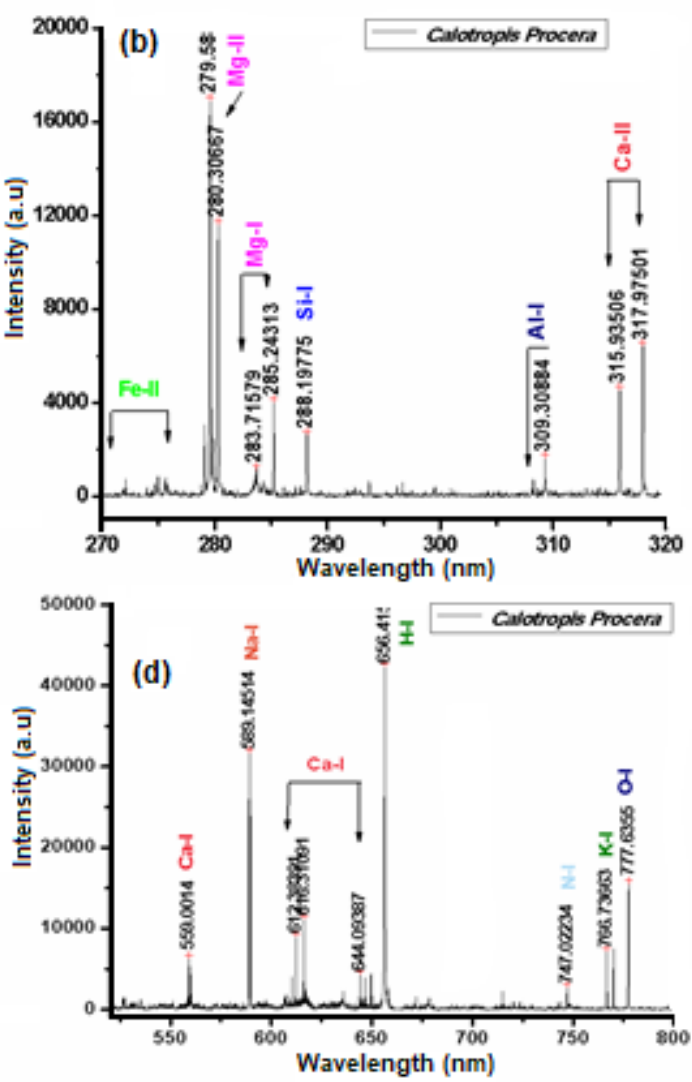

Fig 4. Time-integrated emission spectra of Calotropis procera (a) from 240-270 $\mathrm{nm}$ (b) from 270-320 nm (c) CN band between 384 and 392 (d) 500 to $800 \mathrm{~nm}$ 
Table 2. Prominent wavelengths $\mathrm{CN}$ band of the emission lines [41]

\begin{tabular}{llll}
\hline Samples & Wavelengths $(\mathrm{nm})$ & Vibrational mode & Excitation Energy \\
\hline Caltropis Procera & $385.20,385.76,386.20,387.17$ and 388.37 & $4-4,3-3,2-2,1-1,0-0$ & 3.2 \\
Chenopodium ambrosioides & $385.20,385.76,386.20,387.17$ and 388.37 & $4-4,3-3,2-2,1-1,0-0$ & \\
Nerium Indicum & $385.20,385.76,386.20,387.17$ and 388.37 & $4-4,3-3,2-2,1-1,0-0$ & \\
\hline
\end{tabular}

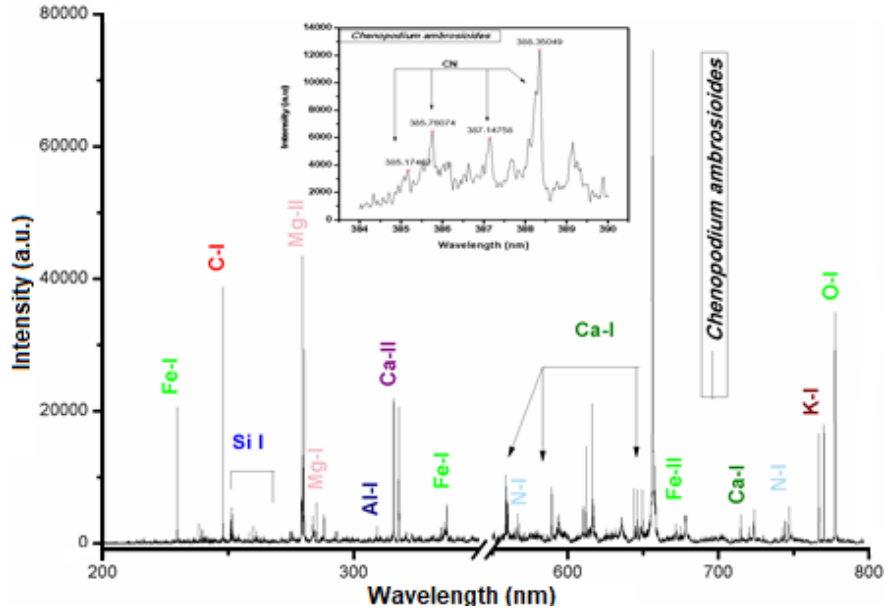

Fig 5. Time-integrated emission spectrum of Chenopodium ambrosioides; inset spectrum confirm $\mathrm{CN}$ band

elements lines have been identified through NIST (NBS) database [40]. Carbon is essential elements while $\mathrm{Si}$ is beneficial trace element. Fig. 4(b) shows the Ca lines at 315.93 and $317.97 \mathrm{~nm}$, while Iron $(\mathrm{Fe})$ at $273.95 \mathrm{~nm}$ with its other lines and $\mathrm{Mg}$ lines at 279.58 and $280.30 \mathrm{~nm}$ were dominant which are essential elements for plants and $\mathrm{Al}$ lines at 308.30 and $309.30 \mathrm{~nm}$ have also detected which is hazardous element but it was detected in trace a mount. In Fig. 4(d) The dominant lines of $\mathrm{Ca}$ and $\mathrm{K}$ which are essential elements for the plant are shown with non mineral element line of $\mathrm{H}_{\alpha}$ corresponding to wavelength 656.41 $\mathrm{nm}$. Sodium is also beneficial mineral elements for the plant was also detected. Fig. 4(c) shows the molecular emission of $\mathrm{CN}$ band at $385.76,386.20,387.17$, and 388.37 $\mathrm{nm}$ respectively in the range of $384-390 \mathrm{~nm}$. Compared to the analysis of metal elements, the plasma formation of LIBS and emission of non metals elements are complex. The interaction between plasma and ambient air was more sensitive for detection of metals under atmospheric pressure and these interactions were analyzed as a result of dissociation of air molecule or recombination between air and plasma were detected as non metals as $\mathrm{O}, \mathrm{N}$ and $\mathrm{CN}$ [19].

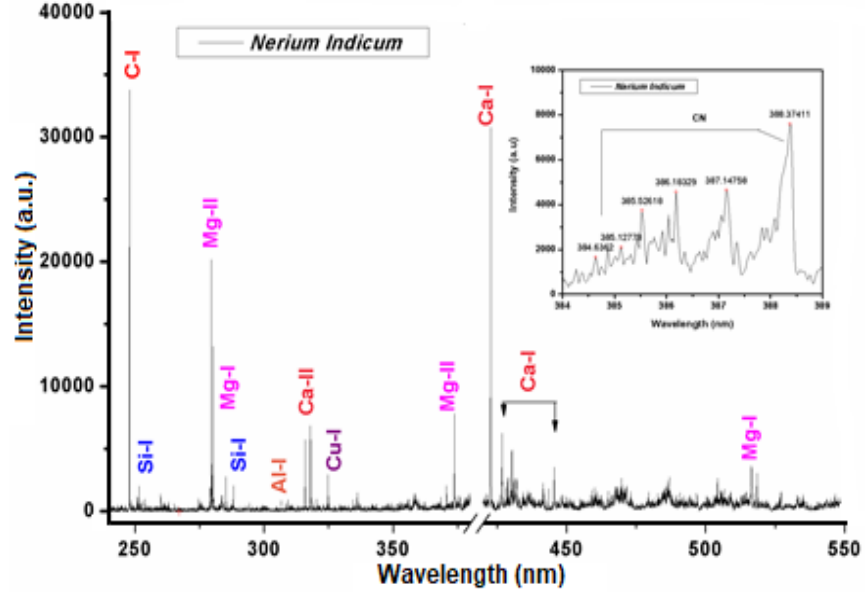

Fig 6. Time-integrated emission spectrum of Nerium indicum ; inset spectrum confirm CN band

In Table 2, prominent wavelengths of $\mathrm{CN}$ band are mentioned. Fig. 5 and 6 shows the time-integrated emission spectra of Chenopodium ambrosioides and Nerium indicum respectively recorded at $45 \mathrm{~mJ}$ laser energy. Both spectra showing clear signatures of $\mathrm{CN}$ band. Pressure-dependent characteristics of spectra are shown in Fig. 8.

The summary of identified elements with their major emission wavelengths is given in Table 3. Timeintegrated studies showing good detection of major, minor and trace elements in all the three samples.

\section{Time-Resolved Studies}

Laser ablation chemical analysis of three medicinal plants leaves was studied by time-resolved LIBS (laserinduced breakdown spectroscopy). Ablation was performed using a fundamental wavelength of Nd: YAG laser in ambient gas environments at a different pressure. We have presented the characteristics of spectra measured from these samples with special attention to atomic and molecular emission. Performance of LIBS can be improved by time resolve detection system to reduce inclusion from continuum emission. 
Table 3. Summary of different emission wavelengths

\begin{tabular}{lll}
\hline Samples & Elements & Major Identifying lines $(\mathrm{nm})$ \\
\hline Calotropis procera; Chenopodium & $\mathrm{C}$ & 247.90 \\
ambrosioides; and Nerium & $\mathrm{H}$ & 656.33 \\
indicum leaves & $\mathrm{O}$ & $777.35,777.58$ \\
& $\mathrm{~N}$ & $742.3,744.2,746.8,868.0,868.33,868.60$ \\
& $\mathrm{Ca}$ & $422.70,643.8,646.2,393.41,396.87,315.91,317.97$ \\
$\mathrm{Mg}$ & $285.22,382.9,383.2,383.8,516.81,517.35,518.42,279.07,279.57,279.81,280.28$ \\
$\mathrm{Na}$ & $588.99,589.59,818.38,818.88$ \\
$\mathrm{~K}$ & $766.41,769.18,404.88$ \\
$\mathrm{Fe}$ & $238.25,259.96,273.95274 .74,337.09,334.95,374.96,438.39$ \\
$\mathrm{Cu}$ & $324.75,327.41,510.57,515.26,521.82$ \\
$\mathrm{Sr}$ & $460.07,407.62$ \\
$\mathrm{Si}$ & $288.18,251.23,251.63,263$ \\
$\mathrm{Al}$ & $308.79,309.29,396.10$ \\
$\mathrm{Ba}$ & $455.42,553.60$ \\
\hline
\end{tabular}
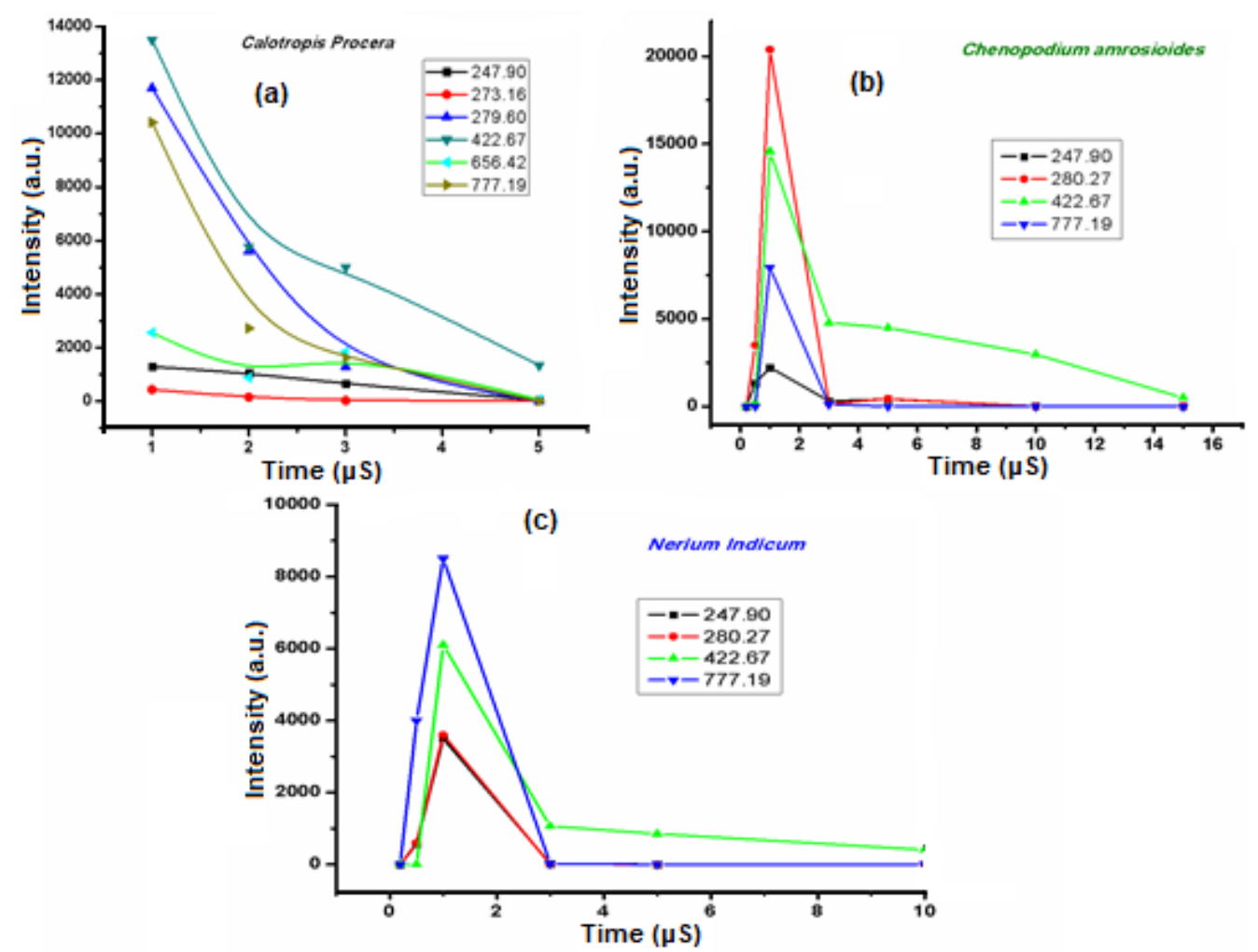

Fig 7. Time-resolved intensity behavior of different elements in (a) Calotropis procera (b) Chenopodium ambrosioides (c) Nerium indicum

To record the time-resolved study of the optical emission from the plasma induced of three samples, At a fixed width of the detection window, there was decrease in emission intensity with increasing delay time. The used detection gate widths for different delays were the same.
Each spectrum was recorded on average of 10 shots. The spectrum shows continuous emission behavior at large delay which contributes to total emission. Bremsstrahlung emission, radiative recombination between electrons and ions were increased significantly as the delay increases. 

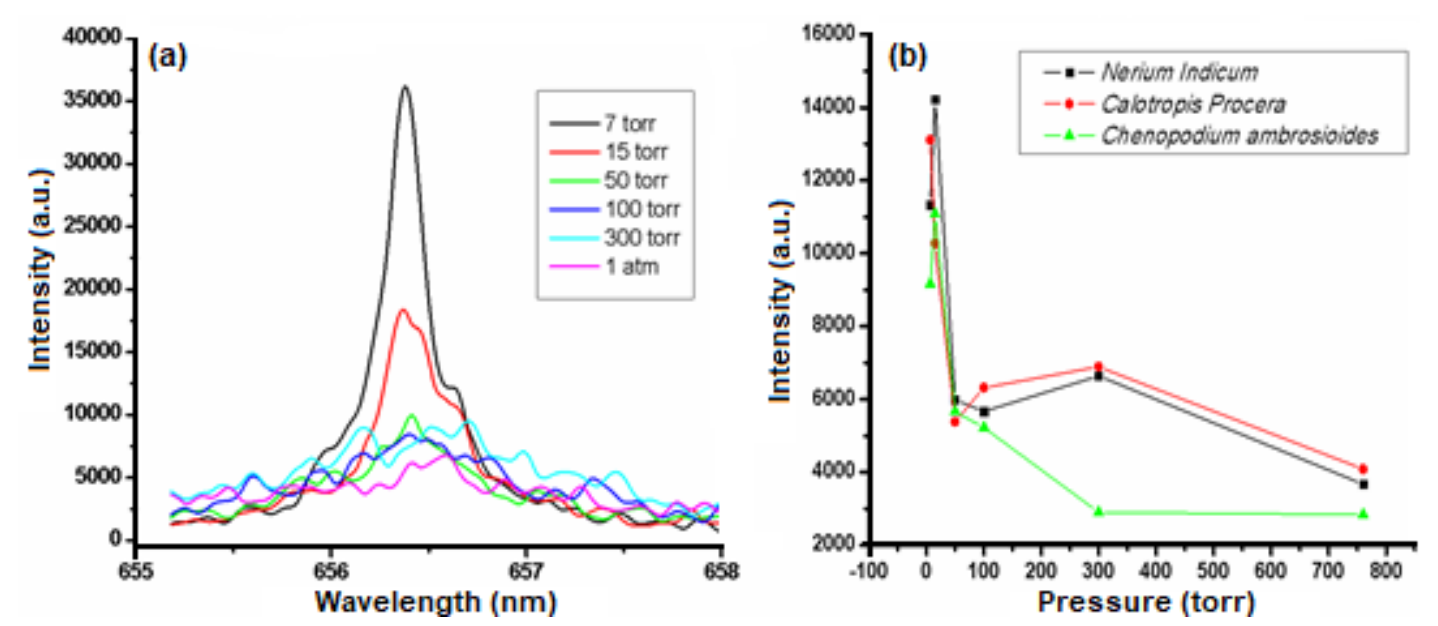

Fig 8. (a) Behaviour of $\mathrm{Ha}$ line at different pressures (b) Intensity behavior of the Ha line at different pressures

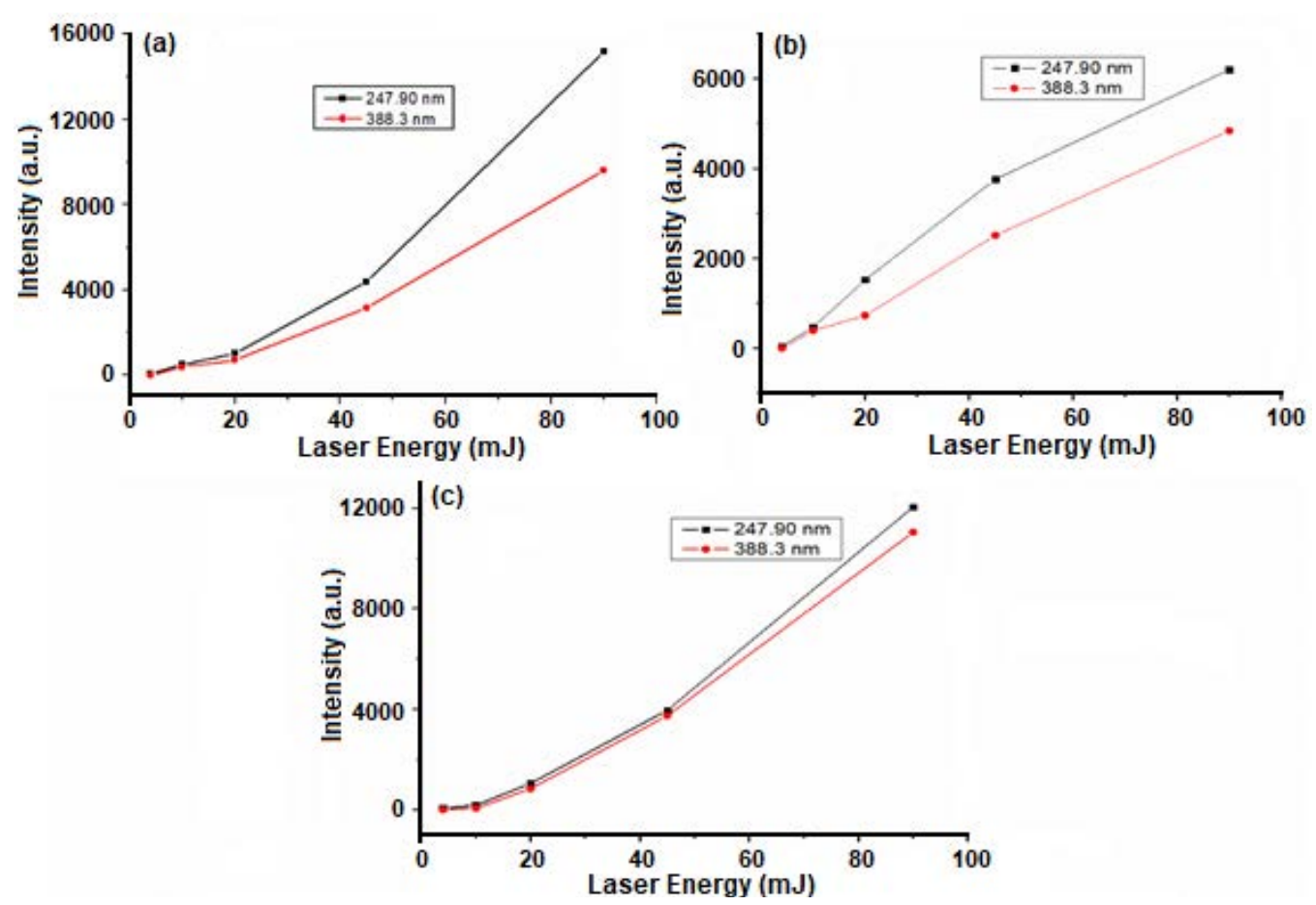

Fig 9. The behavior of emission intensity with different laser energies (a) Calotropis procera (b) Chenopodium ambrosioides (c) Nerium indicum

Fig. 7(a) shows the lifetime of different elements in Calotropis procera at different delay time. It is evident from spectra that all elements show maximum lifetime at $1 \mu \mathrm{s}$ delay while dies off as the delay is increased. We have recorder time-resolved spectra of Chenopodium ambrioisides and Nerium indicum at different delays, 0.5 , 0.2, 1, 3, 5, 10 and $15 \mu$ s respectively as shown in Fig. 7(b) and $7(\mathrm{c})$. The peak intensity of different elements shows their maximum lifetime at $1 \mu \mathrm{s}$. It was very interesting to note the optimum lifetime of these elements in three plants leaves were same.

Fig. 8 shows the behavior of intensity with different air pressures. From the results, it was concluded that the 7 torr was the best pressure to record the leaves data. The integration time and laser energy were fixed during the mesurements. The behavior of emission signals at low pressure has also explained by Suliyanti et al. [2] by focusing Nd: YAG laser on different organic samples at 


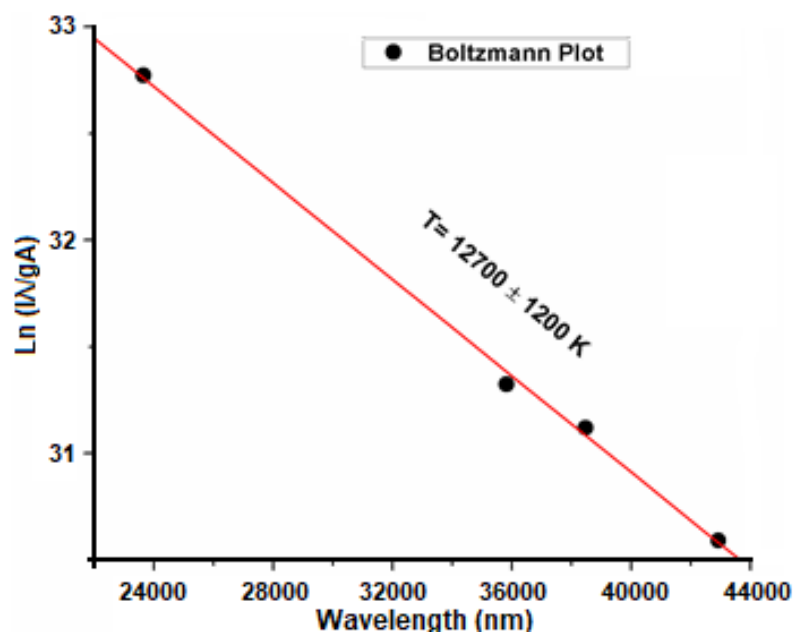

Fig 10. Boltzmann Plot to estimate plasma temperature

low pressure using substrate behind the target. There are two distinct parts of plasma emission at low pressure, in primary part for short period there was continuum emission and in secondary part, there was a strong emission of atomic spectral lines in expanded plasma [2].

Fig. 9 shows the time evolution of $\mathrm{CN}$ band around $388 \mathrm{~nm}$ for variable laser energy at 4,10,20,45, and $90 \mathrm{~mJ}$ respectively. The intensity of the band was maximum at $388.3 \mathrm{~nm}$ which is shown in Fig. 9 as a function of laser energy. The intensity of the C I line at $247.9 \mathrm{~nm}$ is presented in the same figures as a function oflaser energy. The increase in laser energy was due to the increase in the volume of the ablated material and spreading diameter on the target surface. In terms of nanosecond laser pulse, there were two edges of laser pulse named as leading and trailing edges. The trailing edge was used to heat the generated plasma while leading edge interacts with target [42]. These both edges produced a number of atoms, electrons and ions in very short time which produces plasma on leaves surface and this process dissipates laser energy. Enhancements in emission intensity were observed due to this laser pulse. Thus larger the energy there was a great enhancement in intensity [43].

The line intensity of the atomic emission spectra is to measure the population of atoms in corresponding energy levels of that atom. Plasma should be in LTE [44] and for a particular element, the population of an excited atom relates to the number density of neutral atom by Boltzmann's law [45]

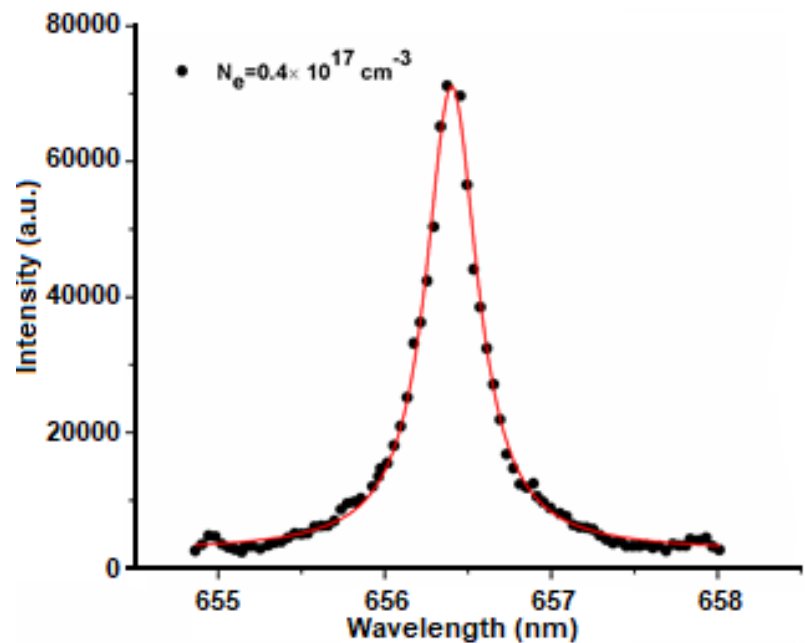

Fig 11. Stark broadened profile of $\mathrm{H}_{\alpha}$ line

$$
I_{k i}=A_{k i} N(T) \frac{h_{c g} e^{\left(-\frac{E_{k}}{K_{B} T_{e}}\right)}}{4 \pi \lambda_{k i} U(T)}
$$

where $\mathrm{k}$ and $\mathrm{i}$ denote the upper and lower energy levels. $\lambda_{\mathrm{ki}}, \mathrm{A}_{\mathrm{ki}}$ and $\mathrm{g}_{\mathrm{k}}$ are, respectively, the wavelength (nm), the transition probability $\left(\mathrm{s}^{-1}\right)$, and the statistical weight for the upper level; $\mathrm{E}_{\mathrm{k}}$ is the excited level energy $\left(\mathrm{cm}^{-1}\right)$; $\mathrm{T}$ is the temperature $(\mathrm{K})$; and $\mathrm{k}$ and $\mathrm{h}$ are Boltzmann $(\mathrm{J} / \mathrm{K})$ and Planck constants (Js), respectively. $\mathrm{U}(\mathrm{T})$ is the partition function. The electron number density and temperature of the plasma are two main parameters on which emission intensity mainly depends. The plasma temperature can be obtained by means of Boltzmann plots. We have chosen Ca I lines to draw Boltzmann plot for all the three samples. The different parameters of these lines are mentioned in Table 4. The Boltzmann plot of Calotropis procerea is shown is shown in Fig. 10. Other samples have similar temperature range with the difference of $\pm 5 \%$.

For the estimation of the electron number density, the full width at half maximum (FWHM) of a Stark broadened line profile of $\mathrm{Ha}$ alpha line was used. The Stark broadened profile for the $\mathrm{Ha}$ alpha line is shown in Fig. 11. The electron number density was also calculated from $\mathrm{H}_{\alpha}$ line by using the following equation [8-9]:

$\mathrm{N}_{\mathrm{e}}=\left(\frac{\mathrm{FWHM}}{1.098}\right)^{1.473} \times 10^{17} \mathrm{~cm}^{-3}$ 
Table 4. Ca lines used for Boltzmann plot

\begin{tabular}{ccccc}
\hline $\begin{array}{c}\text { Wavelength } \\
\lambda(\mathrm{nm})\end{array}$ & \multicolumn{1}{c}{ Transition } & $\begin{array}{c}\text { Upper-level energy } \\
\mathrm{E}_{\mathrm{k}}\left(\mathrm{cm}^{-1}\right)\end{array}$ & $\begin{array}{c}\text { Statistical Weight } \\
\mathrm{g}_{\mathrm{k}}\end{array}$ & $\begin{array}{c}\text { Transition Probability } \\
\mathrm{A}\left(\mathrm{s}^{-1}\right)\end{array}$ \\
\hline 422.67 & $3 \mathrm{p}^{6} 4 \mathrm{~s} 4 \mathrm{p}^{1} \mathrm{P}_{1} \rightarrow 3 \mathrm{p}^{6} 4 \mathrm{~s}^{2}{ }^{1} \mathrm{~S}_{0}$ & 23652.3 & 2 & $2.18 \times 10^{8}$ \\
646.25 & $3 \mathrm{p}^{6} 3 \mathrm{~d} 4 \mathrm{p}^{3} \mathrm{~F}_{3} \rightarrow 3 \mathrm{p}^{6} 3 \mathrm{~d} 4 \mathrm{~s}^{3} \mathrm{D}_{2}$ & 35818.71 & 7 & $4.70 \times 10^{7}$ \\
431.85 & $3 \mathrm{p}^{6} 4 \mathrm{p}^{2}{ }^{3} \mathrm{P}_{1} \rightarrow 3 \mathrm{p}^{6} 4 \mathrm{~s} 4 \mathrm{p}^{3} \mathrm{P}_{2}$ & 38464.8 & 3 & $7.40 \times 10^{7}$ \\
518.84 & $3 \mathrm{p}^{6} 4 \mathrm{~s} 5 \mathrm{~d}^{1} \mathrm{D}_{2} \rightarrow 3 \mathrm{p}^{6} 4 \mathrm{~s} 4 \mathrm{p}^{1} \mathrm{P}_{1}$ & 42919.05 & 5 & $4.00 \times 10^{7}$ \\
\hline
\end{tabular}

FWHM of this line was $0.29 \mathrm{~nm}$ and calculated electron density was $0.4 \times 10^{17} \mathrm{~cm}^{-3}$. All the three plants leaves have approximately same order of magnitude of density values.

\section{- CONCLUSION}

In the present study, we have analyzed three major medicinal plants leaves by using Laser-induced breakdown spectroscopy. The elemental analysis of all the three plants has been done. Some essential elements like $\mathrm{Fe}, \mathrm{Cu}, \mathrm{Mg}, \mathrm{K}, \mathrm{Ca}$ and $\mathrm{Na}$ were detected with major elements $\mathrm{C}, \mathrm{H}, \mathrm{N}$, and $\mathrm{O}$. Some trace elements like $\mathrm{Sr}, \mathrm{Si}$, $\mathrm{Al}$ and $\mathrm{Ba}$ were also detected in all the three plants leave samples. We have also reported the molecular emission of $\mathrm{CN}$ band in all the three organic samples. We have discussed the lifetime of different elements at different delay times to estimate the ideal lifetime of these elements. Characteristic behavior of the emission intensity of $\mathrm{CN}$ band and $\mathrm{C}$ were discussed at different laser energies. We have also described the behavior of intensity at different air pressure. Finally, we have discussed the plasma temperature and electron density which are important characteristics to describe plasma life.

\section{- ACKNOWLEDGMENTS}

Authors are grateful to the Higher Education Commission (HEC) of Pakistan and Mirpur University of Science and Technology (MUST) for financial support.

\section{- REFERENCES}

[1] Kiritkar, K.R., and Basu, B.D., 1999, Indian Medicinal Plants, Bishen Singh and Mahendra Paul Singh, Dehradun, Allahabad, 1664-1666.

[2] Suliyanti, M.M., Sardy, S., Kusnowo, A., Hedwig, R., Abdulmadjid, S.N., Kurniawan, K.H., Lie, T.J., Pardede, M., Kagawa, K., and Tjia, M.O., 2005,
Plasma emission induced by an Nd-YAG laser at low pressure on solid organic sample, its mechanism, and analytical application, J. Appl. Phys., 97 (5), 053305.

[3] Dong, M., Mao, X., Gonzalez, J.J., Lu, J., and Russo, R.E., 2012, Time-resolved LIBS of atomic and molecular carbon from coal in air, argon and helium, J. Anal. At. Spectrom., 27 (12), 2066-2075.

[4] Pardede, M., Hedwig, R., Abdulmadjid, S.N., Lahna, K., Idris, N., Jobiliong, E., Suyanto, H., Marpaung, A.M., Suliyanti, M.M., Ramli, M., Tjia, M.O., Lie, T.J., Lie, Z.S., Kurniawan, D.P., Kurniawan, K.H., and Kagawa, K., 2015, Quantitative and sensitive analysis of $\mathrm{CN}$ molecules using laser induced low pressure He plasma, J. Appl. Phys., 117 (11), 113302.

[5] Lahna, K., Idroes, R., Idris, N., Abdulmadjid, S.N., Kurniawan, K.H., Tjia, M.O., Pardede, M., and Kagawa, K., 2016, Formation and emission characteristics of $\mathrm{CN}$ molecules in laser induced low pressure $\mathrm{He}$ plasma and its applications to $\mathrm{N}$ analysis in coal and fossilization study, App. Opt., 55 (7), 1731-1737.

[6] Rai, S., and Rai, A.K., 2011, Characterization of organic materials by LIBS for exploration of correlation between molecular and elemental LIBS signals, AIP Adv. , 1 (4), 042103.

[7] Tripathi, M., Khanna, S.K., and Das, M., 2004, A novel method for the determination of synthetic colors in ice cream samples, J. AOAC. Int., 87 (3), 657-663.

[8] Miziolek, A.W., Palleschi, V., and Schechter, I., 2006, Laser Induced Breakdown Spectroscopy, Cambridge University Press, New York. 
[9] Noll, R., 2012, Laser-Induced Breakdown Spectroscopy: Fundamental and Applications, Springer, New York.

[10] Griem, H.R., 1961, Plasma Spectroscopy, McGraw Hill, New York.

[11] Singh, J.P., and Thakur, S.N., 2007, Laser-Induced Breakdown Spectroscopy, Elsevier Science, Amsterdam.

[12] Trevizan, L.C., Santos, Jr., D., Samad, R.E., Vieira, Jr., N.D., Nunes, L.C., Rufini, I.A., and Krug, F.J., 2009, Evaluation oflaser induced breakdown spectroscopy for the determination of micronutrients in plant materials, Spectrochim. Acta, Part B, 64 (5), 369-377.

[13] Galiová, M., Kaiser, J., Novotný, K., Novotný, J., Vaculovič, T., Liška, M., Malina, R., Stejskal, K., Adam, V., and Kizek, R., 2008, Investigation of heavy-metal accumulation in selected plant samples using laser induced breakdown spectroscopy and laser ablation inductively coupled plasma mass spectrometry, Appl. Phys. A, 93 (4), 917-922.

[14] Sirven, J.B., Bousquet, B., Canioni, L., Sarger, L., Tellier, S., Potin-Gautier, M., and Le Hecho, I., 2006, Qualitative and quantitative investigation of chromium-polluted soils by laser-induced breakdown spectroscopy combined with neural networks analysis, Anal. Bioanal. Chem., 385 (2), 256-262.

[15] Baudelet, M., Boueri, M., Yu, J., Mao, X., Mao, Y., and Russo, R., 2009, Laser ablation of organic materials for discrimination of bacteria in an inorganic background, Proc. SPIE, 7214, 10.

[16] Vivien, C., Hermann, J., Perrone, A., BoulmerLeborgne, C., and Luches, A., 1998, A study of molecule formation during laser ablation of graphite in low-pressure nitrogen, J. Phys. D: Appl. Phys., 31 (10), 1263.

[17] Baudelet, M., Boueri, M., Yu, J., Mao, Y., Piscitelli, V., Mao, X., and Russo, R., 2007, Time-resolved ultraviolet laser-induced breakdown spectroscopy for organic material analysis, Spectrochim. Acta, Part B, 62 (12), 1329-1334.

[18] Hedwig, R., Lahna, K., Lie, Z.S., Pardede, M., Kurniawan, K.H., Tjia, M.O., and Kagawa, K., 2016, Application of picosecond laser-induced breakdown spectroscopy to quantitative analysis of boron in meatballs and other biological samples, Appl. Opt., 55 (32), 8986-8992.

[19] Boueri, M., Baudelet, M., Yu, J., Mao, X., Mao, S.S., and Russo, R., 2009, Early stage expansion and time-resolved spectral emission of laser-induced plasma from polymer, Appl. Surf. Sci., 255 (24), 9566-9571.

[20] Kurniawan, K.H., Tjia, M.O., and Kagawa, K., 2014, Review of laser-induced plasma, its mechanism, and application to quantitative analysis of hydrogen and deuterium, Appl. Spectrosc. Rev., 49 (5), 323434.

[21] Capitelli, M., Casavola, A., Colonna, G., and De Giacomo, A., 2004, Laser-induced plasma expansion: theoretical and experimental aspects, Spectrochim. Acta, Part B, 59 (3), 271-289.

[22] Zhigilei, L., and Garrison, B., 1999, Mechanisms of laser ablation from molecular dynamics simulations: dependence on the initial temperature and pulse duration, Appl. Phys. A, 69 (Suppl. 1), S75-S80.

[23] Dong, M., Chan, G.C.Y., Mao, X., Gonzalez, J.J., Lu, J., and Russo, R.E., 2014, Elucidation of $\mathrm{C}_{2}$ and $\mathrm{CN}$ formation mechanisms in laser-induced plasmas through correlation analysis of carbon isotopic ratio, Spectrochim. Acta, Part B, 100, 62-69.

[24] Peng, J., and Liu, F., 2018, Comparative study of the detection of chromium content in rice leaves by 532 $\mathrm{nm}$ and $1064 \mathrm{~nm}$ laser-induced breakdown spectroscopy, Sensors, 18 (2), 621.

[25] Andrade, D.F., Pereira-Filho, E.R., and Konieczynski, P., 2017, Comparison of ICP OES and LIBS analysis of medicinal herbs rich in flavonoids from Eastern Europe, J. Braz. Chem. Soc., 28 (5), 838-847.

[26] Rai, P.K., Srivastava, A.K., Sharma, B., Dhar, P., Mishra, A.K., and Watal, G., 2013, Use of laserinduced breakdown spectroscopy for the detection of glycemic elements in Indian medicinal plants, Evid. Based Complement. Alternat. Med., 2013, 406365.

[27] Liu, X., Zhang, Q., Wu, Z., Shi, X., Zhao, N., and Qiao, Y., 2015, Rapid elemental analysis and 
provenance study of Blumea balsamifera DC using laser-induced breakdown spectroscopy, Sensors, 15 (1), 642-655.

[28] Ajaib, M., Khan, Z., Khan, N., and Wahab, M., 2010, Ethnobotanical studies on useful shrubs of district Kotli, Azad Jammu \& Kashmir, Pakistan, Pak. J. Bot., 42 (3), 1407-1415.

[29] Amjad, M.S., Arshad, M., and Chaudhari, S.K., 2013, Phenological patterns among the vegetation of Nikyal valley, district Kotli, Azad Jammu and Kashmir, Pakistan, Br. J. Appl. Sci. Technol., 3 (4), 1505-1518.

[30] Amjad, M.S., Arshad, M., and Chaudhari, S.K., 2014, Structural diversity, its components and regenerating capacity of lesser Himalayan forests vegetation of Nikyal valley District Kotli (AK), Pakistan, Asian Pac. J. Trop. Med., 7 (Suppl. 1), S454-S460.

[31] Mahmood, A., Mahmood, A., Mujtaba, G., Mumtaz, M.S., Kayani, W.K., and Khan, M.A., 2012, Indigenous medicinal knowledge of common plants from district Kotli Azad Jammu and Kashmir Pakistan, J. Med. Plant Res., 635, 4961-4967.

[32] Gomes, A., Das, R., Sarkhel, S., Mishra, R., Mukherjee, S., Bhattacharya, S., and Gomes, A., 2010, Herbs and herbal constituents active against snake bite, Indian J. Exp. Biol., 48 (9), 865-878.

[33] Ur-Rehman, E., 2006, Indigenous knowledge on medicinal plants, village Barali Kass and its allied areas, District Kotli Azad Jammu \& Kashmir, Pakistan, Pak. Ethnobot. Leafl., 10, 254-264.

[34] Jain, S., Sharma, R., Jain, R., and Sharma, R., 1996, Antimicrobial activity of Calotropis procera, Fitoterapia, 67 (3), 275-277.

[35] Ahmad, I., and Beg, A.Z., 2001, Antimicrobial and phytochemical studies on 45 Indian medicinal plants against multi-drug resistant human pathogens, $J$. Ethnopharmacol., 74 (2), 113-123.

[36] Tapondjou, L., Adler, C., Bouda, H., and Fontem, D., 2002, Efficacy of powder and essential oil from Chenopodium ambrosioides leaves as post-harvest grain protectants against six-stored product beetles, J. Stored Prod. Res., 38 (4), 395-402.

[37] Hussain, K., Shahazad, A., and Zia-ul-Hussnain, S., 2008, An ethnobotanical survey of important wild medicinal plants of Hattar district Haripur, Pakistan, Pak. Ethnobot. Leafl., 12, 29-35.

[38] Ahmed, M.J., and Akhtar, T., 2016, Indigenous knowledge of the use of medicinal plants in Bheri, Muzaffarabad, Azad Kashmir, Pakistan, Eur. J. Integr. Med., 8 (4), 560-569.

[39] Hedwig, R., Budi, W.S., Abdulmadjid, S.N., Pardede, M., Suliyanti, M.M., Lie, T.J., Kurniawan, D.P., Kurniawan, K.H., Kagawa, K., and Tjia, M.O., 2006, Film analysis employing subtarget effect using $355 \mathrm{~nm}$ Nd-YAG laser-induced plasma at low pressure, Spectrochim. Acta, Part B, 61 (12), 12851293.

[40] Ralchenko, Y., 2005, NIST atomic spectra database, Mem. Soc. Astron. Ital., 8, 96.

[41] Dong, M., Lu, J., Yao, S., Zhong, Z., Li, J., Li, J., and Lu, W., 2011, Experimental study on the characteristics of molecular emission spectroscopy for the analysis of solid materials containing $\mathrm{C}$ and N, Opt. Express, 19 (18), 17021-17029.

[42] Harilal, S.S., Diwakar, P.K., Polek, M.P., and Phillips, M.C., 2015, Morphological changes in ultrafast laser ablation plumes with varying spot size, Opt. Express, 23 (12), 15608-15615.

[43] Wang, Y., Chen, A., Wang, Q., Sui, L., Ke, D., Cao, S., Li, S., Jiang, Y., and Jin, M., 2018, Influence of distance between focusing lens and target surface on laser-induced $\mathrm{Cu}$ plasma temperature, Phys. Plasmas, 25 (3), 033302.

[44] Huddlestone, R.H., and Leonard, S.L., 1965, Plasma Diagnostic Techniques, $1^{\text {st }}$ ed., Academic Press, New York.

[45] Sabsabi, M., and Cielo, P., 1995, Quantitative analysis of aluminum alloys by laser-induced breakdown spectroscopy and plasma characterization, Appl. Spectrosc., 49 (4), 499-507. 